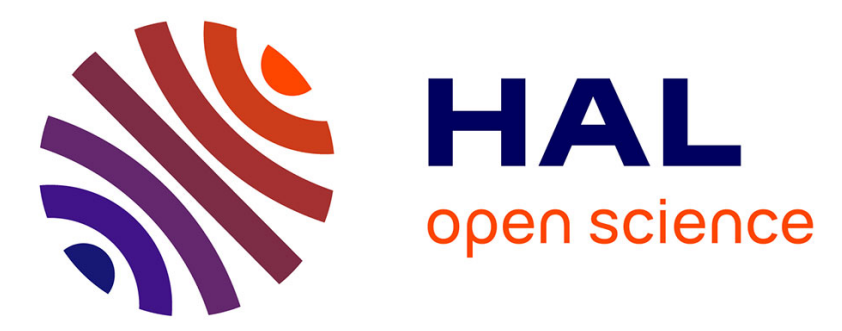

\title{
Chemically stable polyarylether-based covalent organic frameworks
}

Xinyu Guan, Hui Li, Yunchao Ma, Ming Xue, Qianrong Fang, Yushan Yan, Valentin Valtchev, Shilun Qiu

\section{To cite this version:}

Xinyu Guan, Hui Li, Yunchao Ma, Ming Xue, Qianrong Fang, et al.. Chemically stable polyaryletherbased covalent organic frameworks. Nature Chemistry, 2019, 11 (6), pp.587-594. 10.1038/s41557019-0238-5 . hal-03035133

HAL Id: hal-03035133

https://hal-normandie-univ.archives-ouvertes.fr/hal-03035133

Submitted on 2 Dec 2020

HAL is a multi-disciplinary open access archive for the deposit and dissemination of scientific research documents, whether they are published or not. The documents may come from teaching and research institutions in France or abroad, or from public or private research centers.
L'archive ouverte pluridisciplinaire HAL, est destinée au dépôt et à la diffusion de documents scientifiques de niveau recherche, publiés ou non, émanant des établissements d'enseignement et de recherche français ou étrangers, des laboratoires publics ou privés. 


\title{
Chemically stable polyarylether covalent organic
}

\section{frameworks}

\author{
Xinyu Guan, ${ }^{1}$ Hui Li, ${ }^{1}$ Yunchao Ma, ${ }^{1}$ Ming Xue, ${ }^{1}$ Qianrong Fang, ${ }^{1 *}$ Yushan Yan, ${ }^{2 *}$ Valentin \\ Valtchev $^{1,3^{*}}$ and Shilun Qiu ${ }^{1}$
}

${ }^{1}$ State Key Laboratory of Inorganic Synthesis and Preparative Chemistry,

Jilin University, Changchun 130012, China

E-mail:qrfang@jlu.edu.cn

${ }^{2}$ Department of Chemical and Biomolecular Engineering, Center for Catalytic Science and Technology, University of Delaware, Newark, DE 19716, USA

E-mail: yanys@udel.edu

${ }^{3}$ Normandie Univ, ENSICAEN, UNICAEN, CNRS, Laboratoire Catalyse et Spectrochimie, 6 Marechal Juin, 14050 Caen, France

E-mail: valentin.valtchev@ensicaen.fr 


\begin{abstract}
The development of crystalline porous materials (CPMs) with high chemical stability is of paramount importance for their practical uses. Here we report the synthesis of novel polyarylether covalent organic frameworks (PAE-COFs) with high crystallinity, porosity and exceptional chemical stability due to the inert nature of polyarylether building blocks. We demonstrate that these materials can be stable against harsh chemical environments involving boiling water, strong acids/bases, oxidation and reduction conditions, which exceed all known CPMs, including zeolites, metal-organic frameworks (MOFs) and COFs. Furthermore, we explore their advantages as an efficient platform for structural design and functional evolution. The functionalized PAE-COFs combine porosity, high stability, and recyclability, and deliver outstanding performance in the removal of antibiotics from water over a wide $\mathrm{pH}$ range.
\end{abstract}




\section{Introduction}

Covalent organic frameworks (COFs) are an emerging class of crystalline porous materials (CPMs), which are composed of organic building blocks linked by strong covalent bonds. ${ }^{1-6}$ Over the past decade, COFs have attracted wide attention in various application fields including gas adsorption and separation, ${ }^{7-9}$ catalysis, ${ }^{10-13}$ electrochemistry, ${ }^{14-16}$ and a number of others. ${ }^{17-22}$ Nonetheless, the linkages of available COFs are limited to $\mathrm{B}-\mathrm{O}, \mathrm{C}=\mathrm{N}, \mathrm{C}-\mathrm{N}, \mathrm{C}=\mathrm{C}$ and $\mathrm{B}=\mathrm{N}$ bonds. Furthermore, low chemical stabilities, especially in acid and base, present a considerable hindrance to the further development and application of COFs. Although structural stabilities of some COFs can be improved by hydrogen bonds, ${ }^{23}$ keto-enol tautomerism, ${ }^{24}$ enhanced interlayer interactions ${ }^{25}$ or conversion of the imine linkages,${ }^{26}$ these materials do not survive harsh chemical environments, e.g., enhanced acid/base concentration. Design and preparation of a new class of robust COFs that are stable under extreme conditions thus remains a major challenge for bringing these exceptional materials to practical applications.

Polyarylether (PAE) is a highly stable engineered plastic with high heat resistance, excellent chemical stability, good flame retardant properties, and high mechanical robustness. ${ }^{27}$ PAEs can be easily modified with various functional groups ${ }^{28}$ including cyano, carbonyl, carboxyl, and sulfo groups, and thus have broad application prospects in the aerospace, rail transportation, automobile manufacturing, machinery industry and many other technological fields. ${ }^{29}$ Polymers of intrinsic microporosity (PIMs), a new kind of porous material connected by ether bonds, have recently been reported. ${ }^{30}$ However, PIMs are amorphous phases without uniform and ordered pores, which limits their potential applications. The synthesis of crystalline porous PAEs will grant this material with all the advantages of crystalline porous solids, such as a defined channel system that is able to perform recognition and separation of close in size molecules, and an extended micro- and/or mesoporous volume and functional surface with crystallographically defined positions.

Herein, we address the above issues by synthesizing a new kind of polyarylether-based covalent organic frameworks (PAE-COFs) that combine high crystallinity, porosity, and outstanding stability. Two novel PAE-COFs with micropores of $16.8 \AA$ and mesopores of $28.4 \AA$, denoted as JUC-505 and JUC-506 (JUC = Jilin University China), were successfully synthesized. JUC-505 features excellent carbon dioxide $\left(\mathrm{CO}_{2}\right)$ adsorption $\left(231.3 \mathrm{mg} \mathrm{g}^{-1}\right.$ at $273 \mathrm{~K}$ and $189.0 \mathrm{mg} \mathrm{g}^{-1}$ at $\left.298 \mathrm{~K}\right)$ and separation 
(48.9 for $\mathrm{CO}_{2} / \mathrm{CH}_{4}$ and 97.2 for $\mathrm{CO}_{2} / \mathrm{N}_{2}$ ), which are among the highest reported for COF and PIM materials. Remarkably, PAE-COFs maintain their crystallinity after the treatment under harsh chemical environments, including boiling water, strong acids $\left(\mathrm{HCl}, \mathrm{H}_{2} \mathrm{SO}_{4}\right.$ and $\left.\mathrm{HF}\right)$ and bases $(\mathrm{NaOH}$ and $\mathrm{MeONa}$ ), oxidation (chromic acid lotion) and reduction $\left(\mathrm{LiAlH}_{4}\right)$ medium, which outstrips all known CPMs including the aluminosilicate zeolites, metal-organic frameworks (MOFs) and COFs. These COFs with high stability, crystallinity and porosity provide a material platform for structural design and functional development. PAE-COFs with carboxyl or amino functional groups, denoted JUC-505-COOH and JUC-505- $\mathrm{NH}_{2}$, were subsequently obtained by the post-synthetic functionalization, and showed a remarkable performance in the removal of antibiotics from water over a wide $\mathrm{pH}$ range $(\mathrm{pH}=1-13)$.

\section{Results and discussion}

Design of PAE-COFs. Our strategy for preparing PAE-COFs involves aromatic nucleophilic substitution between the extended $o$-difluoro benzene and catechol building units catalyzed by anhydrous potassium carbonate. In the model condensation reaction of tetrafluoroterephthalonitrile (TFTPN) with 1,2-dihydroxybenzene (DHB), fluoride ion and proton are eliminated to yield a dioxin product, 3,13-dicyanobenzo-1,2,4',5'-bis(1,4-benzodioxane) (DCBD, Fig. 1a). On the basis of this reaction, DHB is extended to a triangular building unit, 2,3,6,7,10,11-hexahydroxytriphenylene hydrate (HHTP), whereas TFTPN can be employed directly or replaced by other linear building blocks, such as 2,3,6,7-tetrafluoroanthraquinone (TFAQ). As shown in Fig. 1b, the condensation reaction of HHTP and TFTPN produces a two-dimensional (2D) microporous crystalline JUC-505 with hexagonal pores of 16.8 $\AA$. On the other hand, replacing TFTPN with a longer linker, TFAQ, gives 2D mesoporous JUC-506 with larger hexagonal pores of $28.4 \AA$ (Fig. 1c). By linking the linear and triangular building units through the aromatic nucleophilic substitution reaction, the products form $2 \mathrm{D}$ structures based on the boron nitride net (bnn, Fig. 1d).

Synthesis and characterization. Typically, PAE-COFs were synthesized by suspending anhydrous potassium carbonate, HHTP with TFTPN or TFAQ in a mixed solution of $N$-methyl-2-pyrrolidone (NMP) and mesitylene followed by heating at $120^{\circ} \mathrm{C}$ and $160{ }^{\circ} \mathrm{C}$ for 3 days, giving crystalline solids at yields of $84 \%$ for JUC-505 and $78 \%$ for JUC-506, respectively. Scanning electron microscopy (SEM) inspection revealed that both materials exhibit fiber-like particles with a cross section diameter of about 
$100 \mathrm{~nm}$. The length of fiber-like particles is several hundred nanometers in the case of JUC-505, while up to 10 micron fibers can be seen in the case of JUC-506 (Figs. S1 and S2). Fourier transform infrared (FTIR) spectra displayed adsorption peaks at $1264 \mathrm{~cm}^{-1}$ and $1021 \mathrm{~cm}^{-1}$ for JUC-505 and $1270 \mathrm{~cm}^{-1}$ and $1031 \mathrm{~cm}^{-1}$ for JUC-506 corresponding to asymmetric and symmetric vibration modes of the ether bonds, respectively, which is consistent with those from the model compound DCBD $\left(1274 \mathrm{~cm}^{-1}\right.$ and 1030 $\mathrm{cm}^{-1}$, Figs. S5-7). Noteworthy, the significant decrease at $3432 \mathrm{~cm}^{-1}$ (referring to $\mathrm{OH}$ stretching of the starting material HHTP) was observed, indicating a high-conversion polymerization. Solid-state ${ }^{13} \mathrm{C}$ cross polarization magic-angle-spinning (CP/MAS) nuclear magnetic resonance (NMR) analysis resulted in the exact attribution for each peak and further confirmed the formation of PAE-COFs (Figs. S9 and S10). Elemental analysis of PAE-COFs was in good agreement with the expected formulas of $\mathrm{C}_{10} \mathrm{H}_{2} \mathrm{O}_{2} \mathrm{~N}$ for JUC-505 and $\mathrm{C}_{13} \mathrm{H}_{4} \mathrm{O}_{3}$ for JUC-506, respectively. The content of residue fluorine was further determined by energy dispersive spectrometer (EDS) as $0.94 \%$ for JUC-505 and $0.49 \%$ for JUC-506 (Figs. S13 and S15). Furthermore, the reaction conversions were calculated from residue fluorine content as $95.3 \%$ for PAE-505 and $96.9 \%$ for PAE-506.

Crystallinity and structural resolution. The crystallinity and unit cell parameters of PAE-COFs were determined by powder X-ray diffraction (PXRD) analysis. Data obtained with the Materials Studio software package based on of the eclipsed 2D bnn net show that both PAE-COFs crystallize in P6/mmm (No. 197) space group (Figs. S17, S20, Tables S1 and S3). ${ }^{31}$ After a geometrical energy minimization using the universal force field, the unit cell parameters were obtained $(a=b=24.6865 \AA$, $c=3.5002 \AA, \alpha=\beta=90^{\circ}$ and $\gamma=120^{\circ}$ for JUC-505; $a=b=33.7458 \AA, c=3.4702 \AA, \alpha=\beta=90^{\circ}$ and $\gamma=120^{\circ}$ for JUC-506). The simulated PXRD patterns were in good agreement with the experimental ones (Fig. 2, a and b). Furthermore, full profile pattern matching (Pawley) refinements were carried out on the experimental PXRD patterns. Peaks at $2 \theta=4.12,7.13,8.24,10.93$ and $14.88^{\circ}$ for JUC-505 and $3.02,5.23,6.04,8.00$ and $10.91^{\circ}$ for JUC-506 correspond to the (100), (110), (200), (210) and (310) planes, respectively. The refinement results yielded unit cell parameters nearly equivalent to the predictions with good agreement factors $\left(a=b=24.7714 \AA, c=3.4624 \AA, \alpha=\beta=90^{\circ}, \gamma=120^{\circ}, \omega R \mathrm{p}=\right.$ $2.02 \%$ and $R \mathrm{p}=1.60 \%$ for JUC-505; $a=b=33.9363 \AA, c=3.5704 \AA, \alpha=\beta=90^{\circ}, \gamma=120^{\circ}, \omega R \mathrm{p}=$ $5.71 \%$ and $R \mathrm{p}=3.07 \%$ for JUC-506). We also considered an alternative staggered $2 \mathrm{D}$ arrangement (AB stacking) in which the units of adjacent sheets are horizontally offset by a distance of $a / 2$ and $b / 2$ (Figs. S18, S21, Tables S2 and S4). The simulated PXRD pattern for this arrangement does not match 
the experimental data (Figs. S19 and S22). On the basis of these results, JUC-505 and JUC-506 were proposed to have the eclipsed stacking architectures with hexagonal micropores of about $16.8 \AA$ and hexagonal mesopores of $28.4 \AA$, respectively (Fig. 2, c and d). The formation of the eclipsed structure can be attributed to the strong tendency for aromatic units to form cofacial aggregates between adjacent layers.

Gas adsorption and separation. Nitrogen $\left(\mathrm{N}_{2}\right)$ adsorption-desorption analysis of JUC-505 measured at $77 \mathrm{~K}$ showed a type $\mathrm{I}$ isotherm with a sharp uptake at a low pressure of $\mathrm{P} / \mathrm{P}_{0}<0.05$, which is characteristic of microporous material (Fig. 3a). Meanwhile, $\mathrm{N}_{2}$ adsorption-desorption isotherm of JUC-506 showed a rapid uptake at a low pressure of $\mathrm{P} / \mathrm{P}_{0}<0.1$, followed by a sharp step between $\mathrm{P} / \mathrm{P}_{0}$ $=0.15$ and 0.25 (Fig. 3b). This sorption profile is best described as a type IV isotherm, which is characteristic of mesoporous materials. The total pore volumes were evaluated at $\mathrm{P} / \mathrm{P}_{0}=0.95$ to be $\mathrm{Vp}$ $=0.51 \mathrm{~cm}^{3} \mathrm{~g}^{-1}$ for JUC-505 and $0.71 \mathrm{~cm}^{3} \mathrm{~g}^{-1}$ for JUC-506. Pore size distributions of PAE-COFs calculated on the basis of nonlocal density functional theory (NLDFT) showed pore with sizes of 16.2 $\AA$ for JUC-505 and $30.1 \AA$ for JUC-506, respectively (Fig. $3 \mathrm{a}$ and b, inset), which is in good agreement with that of the proposed model (16.8 $\AA$ for JUC-505 and $28.4 \AA$ for JUC-506). The Brunauer-Emmett-Teller (BET) equation was applied over the $0.02<\mathrm{P} / \mathrm{P}_{0}<0.20$ range of the isotherms, revealing BET surface areas of $1584 \mathrm{~m}^{2} \mathrm{~g}^{-1}$ for JUC-505 and $1655 \mathrm{~m}^{2} \mathrm{~g}^{-1}$ for JUC-506 (Figs. S28 and S29).

Considering the high crystallinity, excellent porosity and affinity to $\mathrm{CO}_{2}$ of $\mathrm{PIMs},{ }^{30}$ we studied the potential application of PAE-COFs for $\mathrm{CO}_{2}$ adsorption and separation. The adsorption isotherms of $\mathrm{CO}_{2}, \mathrm{~N}_{2}$, and $\mathrm{CH}_{4}$ were measured at $273 \mathrm{~K}$ and $298 \mathrm{~K}$, respectively. As shown in Figs. 3, S32 and S33, the sorption amounts of $\mathrm{CO}_{2}$ are as high as $231.3 \mathrm{mg} \mathrm{g}^{-1}$ for JUC-505 and $203.0 \mathrm{mg} \mathrm{g}^{-1}$ for JUC-506 at $273 \mathrm{~K}$, and the $\mathrm{CO}_{2}$ sorption analysis at $298 \mathrm{~K}$ shows the capacity of $189.0 \mathrm{mg} \mathrm{g}^{-1}$ for JUC-505 and $159.2 \mathrm{mg} \mathrm{g}^{-1}$ for JUC-506. Thus, JUC-505 exhibits the highest $\mathrm{CO}_{2}$ uptake among COFs and PIMs reported to date, such as PyTTA-BFBIm-iCOF $(177 \mathrm{mg} / \mathrm{g} \text { at } 273 \mathrm{~K})^{32}$ and TZPIMs $(132 \mathrm{mg} / \mathrm{g}$ at 273 K). ${ }^{33}$ Meanwhile, the $\mathrm{CO}_{2}$ uptake is much higher with respect to other gases such as $\mathrm{CH}_{4}\left(19.2 \mathrm{mg} \mathrm{g}^{-1}\right.$ for JUC-505 and $18.3 \mathrm{mg} \mathrm{g}^{-1}$ for JUC-506 at $273 \mathrm{~K} ; 15.2 \mathrm{mg} \mathrm{g}^{-1}$ for JUC-505 and $13.1 \mathrm{mg} \mathrm{g}^{-1}$ for JUC-506 at $298 \mathrm{~K})$ and $\mathrm{N}_{2}\left(10.4 \mathrm{mg} \mathrm{g}^{-1}\right.$ for JUC-505 and $8.8 \mathrm{mg} \mathrm{g}^{-1}$ for JUC-506 at $273 \mathrm{~K} ; 12.5 \mathrm{mg} \mathrm{g}^{-1}$ for JUC-505 and $8.9 \mathrm{mg} \mathrm{g}^{-1}$ for JUC-506 at $298 \mathrm{~K}$ ). The ideal adsorption selectivity of PAE-COFs was calculated from the ratio of the initial slopes in the Henry region of the isotherms (Figs. S34-S37), ${ }^{34}$ 
and high selectivity of $\mathrm{CO}_{2} / \mathrm{N}_{2}$ and $\mathrm{CO}_{2} / \mathrm{CH}_{4}$ was observed (Table 1). For example, the ideal adsorption selectivity of JUC-505 is as high as 48.9 for $\mathrm{CO}_{2} / \mathrm{CH}_{4}$ and 97.2 for $\mathrm{CO}_{2} / \mathrm{N}_{2}$ at $273 \mathrm{~K}$, respectively. Furthermore, preliminary breakthrough experiments for JUC-505 were carried out by exposing to streams containing binary mixtures of $\mathrm{CO}_{2} / \mathrm{N}_{2}$ or $\mathrm{CO}_{2} / \mathrm{CH}_{4}(50: 50 \mathrm{v} / \mathrm{v})$ at room temperature. The results clearly showed that in both cases only $\mathrm{CO}_{2}$ was retained in the pores of JUC-505 while $\mathrm{N}_{2}$ and $\mathrm{CH}_{4}$ passed through without impediment (Fig. 3 e and f).

Stability of PAE-COFs. Similar to amorphous PAEs, crystalline PAE-COFs displays outstanding thermal and chemical stability. According to the thermogravimetric analysis (TGA), PAE-COFs are thermally stable up to $400{ }^{\circ} \mathrm{C}$ under nitrogen (Figs. S38 and S39). To investigate the chemical stability of PAE-COFs, we exposed JUC-505 and JUC-506 samples to different chemical environments for one week, including various organic solvents (e.g., NMP, $N, N$-dimethylformamide (DMF), tetrahydrofuran (THF), dichloromethane (DCM), ethanol (EtOH), acetone, n-hexane and $m$-cresol), boiling water, concentrated $\mathrm{HCl}(12 \mathrm{M})$, concentrated $\mathrm{H}_{2} \mathrm{SO}_{4}(18 \mathrm{M}), \mathrm{HF}(40 \%)$, concentrated $\mathrm{NaOH}(14 \mathrm{M}), \mathrm{MeONa}$ (5 $\mathrm{M}$ in $\mathrm{MeOH})$, chromic acid lotion $\left(0.1 \mathrm{M} \mathrm{K}_{2} \mathrm{Cr}_{2} \mathrm{O}_{7}\right.$ in concentrate $\left.\mathrm{H}_{2} \mathrm{SO}_{4}\right)$ and $\mathrm{LiAlH}_{4}(2.4 \mathrm{M}$ in THF). JUC-505 and JUC-506 retain their original skeleton and crystalline structure after the treatment under the above conditions as demonstrated by unaltered position and strength of the peaks in their PXRD patterns (Figs. 2e and S42) and the retained ether bond in the IR spectra (Figs. 2f and S45). Moreover, $\mathrm{N}_{2}$ adsorption isotherms at $77 \mathrm{~K}$ after the treatment are very close to those of as-synthesized materials, which further confirmed the preserved porosity (Figs. S46 and S47). For the sake of comparison, we tested the chemical stability of the typically stable COFs reported to date, including

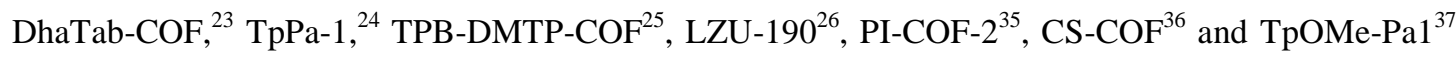
(Figs. S48-S54). On the basis of the PXRD analysis, TpPa-1, PI-COF-2, LZU-190, CS-COF, TpOMe-Pa1 and DhaTab-COF are not stable in extreme alkaline medium whereas TPB-DMTP-COF, PI-COF-2 and DhaTab-COF cannot withstand strong acid. Noteworthy, none of these most stable COFs retains crystallinity after the treatment with concentrate $\mathrm{H}_{2} \mathrm{SO}_{4}$ or chromic acid lotion. Furthermore, some typical MOFs (e.g., UiO- $66^{38}$, ZIF- $^{39}{ }^{3}$ HKUST- $1^{40}$ and MOF- $5^{41}$ ) and zeolites (commercial Silicalite-1, $\mathrm{X}, \mathrm{Y}$ and 4A) were also selected for the stability test, and none of these matters retained entire crystallinity after the treatment as can be seen in Table 2 and Figs. S55-S62. These results unambiguously prove the outstanding chemical stability of PAE-COFs which surpasses all known crystalline porous materials. 
Functionalization of PAE-COFs. In order to extend the possible applications, JUC-505 was transformed into an open framework with functional sites by the chemical modification of cyano groups (Figs. 1b, S20, S21, Tables S5 and S6). Carboxyl or amino functionalized PAE-COFs, JUC-505-COOH and JUC-505- $\mathrm{NH}_{2}$, were obtained by refluxing JUC-505 in $\mathrm{NaOH}(20 \%$ in ethanol/water $=1 / 1)^{42}$ and $\mathrm{LiAlH}_{4}(2.4 \mathrm{M}$ in THF $){ }^{43}$ respectively. SEM images of functionalized JUC-505 derivatives exhibited similar morphology to the parent material (Figs. S3 and S4). Adsorption peaks of IR spectra at $1268 \mathrm{~cm}^{-1}$ and $1021 \mathrm{~cm}^{-1}$ for JUC-505-COOH as well as $1264 \mathrm{~cm}^{-1}$ and 1022 $\mathrm{cm}^{-1}$ for JUC-505- $\mathrm{NH}_{2}$, corresponding to asymmetric and symmetric vibration modes of the ether bonds, were consistent with those of the pristine structure $\left(1264 \mathrm{~cm}^{-1}\right.$ and $1021 \mathrm{~cm}^{-1}$ for JUC-505, Fig. S8). Peaks at $1716 \mathrm{~cm}^{-1}$ for JUC-505-COOH and $3293 \mathrm{~cm}^{-1}$ for JUC-505- $\mathrm{NH}_{2}$ indicated the grafting of carboxyl and amino group on the respective COFs. A significant decrease of the peak at $2239 \mathrm{~cm}^{-1}$ demonstrated the high transformation ratios of cyano groups for both post-modifications. Furthermore, the peaks at $163 \mathrm{ppm}$ for JUC-505-COOH and $25 \mathrm{ppm}$ for $\mathrm{JUC}-505-\mathrm{NH}_{2}$ from the solid-state ${ }^{13} \mathrm{C}$ CP/MAS NMR analysis confirmed the presence of carboxyl and aminomethyl groups, respectively (Figs. S11 and S12). The PXRD patterns of JUC-505-COOH and JUC-505-NH 2 were identical to JUC-505 (Fig. S23), which showed that the framework was not affected by the grafting. Conversation rates were further determined by $\mathrm{CHN}$ elemental analysis as $98.6 \%$ for JUC-505-COOH and $94.6 \%$ for JUC-505- $\mathrm{NH}_{2}$. The porosities of JUC-505-COOH and JUC-505- $\mathrm{NH}_{2}$ were evaluated by $\mathrm{N}_{2}$-sorption isotherm measurements. Both matters showed typical type I isotherms (Figs. S26 and S27), and the BET surface areas were reduced slightly with respect to the parent material $\left(1392 \mathrm{~m}^{2} \mathrm{~g}^{-1}\right.$ for JUC-505-COOH and $1244 \mathrm{~m}^{2} \mathrm{~g}^{-1}$ for JUC-505-NH $\mathrm{NH}_{2}$, Figs. S30 and S31).

Adsorptive removal of antibiotics. Antibiotics, as one of the major classes of pharmaceuticals and personal care products, are widely used in hospitals, households, and veterinary applications, and their production and usage increase every year. ${ }^{44}$ However, when released into the environment, they can promote the development of resistance in microbial populations and induce toxic effects on aquatic organisms. ${ }^{45}$ Tetracycline antibiotics (TCA) are among the most widely used ones. As an experimental proof-of-concept, three common species of TCA including tetracycline (TC), oxytetracycline (OTC) and chlortetracycline hydrochloride (CTC) were chosen for the adsorption test. The parent JUC-505 and functionalized PAE-COFs (JUC-505-COOH and JUC-505- $\mathrm{NH}_{2}$ ) were activated to remove guest molecules and then immersed in antibiotic solutions at $\mathrm{pH}=1-13$ for 3 days. The residual 
concentrations and the medical uptake were determined by UV-Vis spectroscopy and calculated according to the standard curve.

As shown in Fig. 4 a-c, carboxyl-decorated JUC-505-COOH reveals a larger uptake capacity in acidic solutions (e.g., $245.8 \mathrm{mg} / \mathrm{g}$ for TC, $213.8 \mathrm{mg} / \mathrm{g}$ for OTC and $238.9 \mathrm{mg} / \mathrm{g}$ for CTC at $\mathrm{pH}=1$ ) while amino-functionalized JUC-505- $\mathrm{NH}_{2}$ shows better performance under strongly alkaline conditions (e.g., $247.3 \mathrm{mg} / \mathrm{g}$ for TC, $237.0 \mathrm{mg} / \mathrm{g}$ for OTC and $274.6 \mathrm{mg} / \mathrm{g}$ for $\mathrm{CTC}$ at $\mathrm{pH}=13$ ), which can be attributed to the hydrogen bond and electrostatic interactions at different $\mathrm{pHs}$. These values prove high adsorbing capacities under extreme $\mathrm{pH}$ values, which is superior to the best performance materials reported for antibiotic assimilation, such as resins, clays, carbon nanotubes, zeolites, and MOFs. ${ }^{46-49} \mathrm{We}$ also tested the reusability of PAE-COFs after antibiotics removal. After being immersed in concentrated $\mathrm{HCl}$ for $1 \mathrm{~h}$, filtered and washed with water, PAE-COFs were reused for the antibiotics removal. The sorption and release process was repeated for five continuous cycles, and the procedure was reversible with almost no loss of capacity (Fig. 4 d-i). These results suggest that the extremely stable PAE-COFs with high adsorption capacities are excellent materials for antibiotics removal that can be used under extreme conditions, regardless of the $\mathrm{pH}$ value.

\section{Conclusion}

In summary, we have developed a novel series of crystalline, porous and highly stable COF materials, PAE-COFs, by regulating the crystallization of ultra-highly stable polyarylether. PAE-COFs are thermally stable up to $400{ }^{\circ} \mathrm{C}$ and extremely resistant to various chemical environments, including boiling water, strong acids and bases, oxidation and reduction atmosphere, which surpasses all known crystalline porous materials including zeolites, MOFs and COFs. PAE-COFs showed impressive $\mathrm{CO}_{2}$ adsorption capacity and $\mathrm{CO}_{2} / \mathrm{CH}_{4}$ and $\mathrm{CO}_{2} / \mathrm{N}_{2}$ selectivities. A member of the family (JUC-505) recorded the highest $\mathrm{CO}_{2}$ uptake $\left(231.3 \mathrm{mg} \mathrm{g}^{-1}\right.$ at $273 \mathrm{~K}$ ) overpassing all COFs and PIMs reported to date. Carboxyl or amino functionalized PAE-COFs showed exceptional abilities for antibiotics removal from water covering the $\mathrm{pH}$ range of 1-13. These stable novel COFs are a perfect platform for the preparation of functional materials that can be used under extreme chemical environments. Finally, this study shows that the most significantdisadvantage of COF materials, their limited chemical stability, can be overcome by proper design of their skeletons based on new stable bonds.

\section{Methods}


Synthesis of TFAQ. ${ }^{50}$ A mixture of 4,5-difluorophthalic anhydride $(5.0 \mathrm{~g}, 27.2 \mathrm{mmol})$ and 1,2-difluorobenzene $(16.0 \mathrm{~mL}, 165.0 \mathrm{mmol})$ was heated to $60^{\circ} \mathrm{C}$ and stirred for $20 \mathrm{mins}$. After cooling to room temperature $(\mathrm{RT}), \mathrm{AlCl}_{3}(7.9 \mathrm{~g}, 54.0 \mathrm{mmol})$ was carefully added to the mixture in small portions. The resultant dark brown solution was stirred at RT for $4 \mathrm{hrs,} \mathrm{and} \mathrm{then} \mathrm{the} \mathrm{reaction} \mathrm{mixture}$ was cooled to $0^{\circ} \mathrm{C}$ and $1 \mathrm{M} \mathrm{HCl}$ was slowly added. The white precipitate obtained from the reaction was dissolved in $\mathrm{Et}_{2} \mathrm{O}$, and the organic phase was washed with $1 \mathrm{M} \mathrm{HCl}$ and water and dried over $\mathrm{Na}_{2} \mathrm{SO}_{4}$, and then concentrated under vacuum. Recrystallized from $\mathrm{CH}_{2} \mathrm{Cl}_{2}$ /hexane gave pure TFAQ as a pale-brown solid $(7.4 \mathrm{~g}, 91 \%)\left(\mathrm{Rf}=0.35\right.$ with $\left.\mathrm{CHCl}_{3} / \mathrm{MeOH} 10: 1\right)$; m.p. $123{ }^{\circ} \mathrm{C} ;{ }^{1} \mathrm{H} \mathrm{NMR}(600 \mathrm{MHz}$, $\left.\mathrm{CDCl}_{3}\right): \mathrm{d}=7.96(\mathrm{t}, \mathrm{J}=9.0 \mathrm{~Hz}, 1 \mathrm{H}), 7.63(\mathrm{t}, \mathrm{J}=8.4 \mathrm{~Hz}, 1 \mathrm{H}), 7.41($ br s, 1H), 7.23-7.19 ppm (m, 2H); IR (KBr): 3072-2581, 1685, 1611, 1590, 1519, 1435, 1321, 1285, 1180, $904 \mathrm{~cm}^{-1}$.

Synthesis of the model DCBD compound. The model compound, 3,13-dicyanobenzo-1,2,4',5'-bis(1, 4-benzodioxane) (DCBD), was prepared as described previously in the thioamide PIM-1 paper. ${ }^{51}$ Anhydrous DMF (60.0 $\mathrm{mL})$ was added to 1,2-dihydroxybenzene $(2.2 \mathrm{~g}, 20.4 \mathrm{mmol})$, tetrafluoroterephthalonitrile $(1.9 \mathrm{~g}, 9.3 \mathrm{mmol})$, and potassium carbonate $(8.0 \mathrm{~g}, 57.8 \mathrm{mmol})$ under an inert atmosphere. The reaction was heated to $65^{\circ} \mathrm{C}$ and kept at this temperature for $24 \mathrm{hrs}$. The mixture was cooled to RT, and the solid was collected via vacuum filtration. The crude product was then stirred in water $(150.0 \mathrm{~mL})$ for $1 \mathrm{hr}$ and acetone $(150.0 \mathrm{~mL})$ for $1 \mathrm{hr}$ before being dried in an oven at $110^{\circ} \mathrm{C}$ overnight. DCBD was obtained as a yellow solid (2.9 g, 90\% yield). ${ }^{1} \mathrm{H}$ NMR (400 MHz, DMSO- $\left.d 6\right) \delta$ : 7.25-7.00 ppm (m, 8H). IR (KBr): 2240, 1607, 1498, 1446, 1099, $1029 \mathrm{~cm}^{-1}$.

Synthesis of JUC-505. A Pyrex tube measuring o.d. $\times$ i.d. $=10 \times 8 \mathrm{~mm}^{2}$ was charged with anhydrous $\mathrm{K}_{2} \mathrm{CO}_{3}(138.2 \mathrm{mg}, 1.0 \mathrm{mmol})$, HHTP $(32.4 \mathrm{mg}, 0.1 \mathrm{mmol})$ and TFTPN (30.0 $\left.\mathrm{mg}, 0.15 \mathrm{mmol}\right)$ in a solution of $0.30 \mathrm{~mL}$ mesitylene/0.60 mL NMP. The tube was flash frozen at $77 \mathrm{~K}\left(\mathrm{LN}_{2}\right.$ bath), evacuated to an internal pressure of $0.15 \mathrm{mmHg}$ and flame sealed. Upon sealing the length of the tube was reduced to ca. $13.0 \mathrm{~cm}$. The reaction mixture was heated at $120{ }^{\circ} \mathrm{C}$ for 3 days and the obtained brown precipitate was isolated by filtration over a medium glass frit and washed with DMF $(20.0 \mathrm{~mL} \times$ $3), \mathrm{H}_{2} \mathrm{O}(20.0 \mathrm{~mL} \times 3)$ and acetone $(20.0 \mathrm{~mL} \times 3)$. The solvent was then exchanged with anhydrous acetone and removed under vacuum at $80{ }^{\circ} \mathrm{C}$ to afford JUC-505 as a brown powder $(42.1 \mathrm{mg}, 84 \%)$. The degree of crystallinity was calculated from PXRD pattern by $\mathrm{Jade}^{52}$ as $91.9 \%$. Solid-state ${ }^{13} \mathrm{C}$ NMR (500 MHz) d: 145.5, 137.8, 125.5, 109.7, 93.4. IR (KBr): 3077, 3028, 2239, 1681, 1624, 1506, 1460, 
1264, 1185, 1021, 982, $877 \mathrm{~cm}^{-1}$. Anal. Calcd: C, 71.44; H, 1.20; N, 8.33. Found: C, 70.76; H, 1.17; N, $8.14 ; \mathrm{F}, 0.95$.

Synthesis of JUC-506. In a manner similar to the preparation of JUC-505, treatment of $\mathrm{K}_{2} \mathrm{CO}_{3}(138.2$ $\mathrm{mg}, 1.0 \mathrm{mmol})$, HHTP $(32.4 \mathrm{mg}, 0.1 \mathrm{mmol})$ and TFAQ $(42.0 \mathrm{mg}, 0.15 \mathrm{mmol})$ in a solution of $0.30 \mathrm{~mL}$ mesitylene/ $0.60 \mathrm{~mL} \mathrm{NMP}$ at $160{ }^{\circ} \mathrm{C}$ for 3 days yielded a brown precipitate $(48.7 \mathrm{mg}, 78 \%$ ), which was subjected to purification by the above described procedure. The degree of crystallinity was calculated from PXRD pattern by Jade as 85.1\%. Solid-state ${ }^{13} \mathrm{C}$ NMR (500 MHz) d: $177.4,144.9,138.9,129.1$, 125.0, 113.8, 109.2. IR (KBr): 3071, 1676, 1578, 1519, 1493, 1270, 1179, 1041, 982, $864 \mathrm{~cm}^{-1}$. Anal. Calcd: C, 75.01; H, 1.94. Found: C, 74.64; H, 1.92; F, 0.49.

Synthesis of JUC-505-COOH. JUC-505 powder $(200.0 \mathrm{mg})$ and $20 \% \mathrm{NaOH}$ solution $\left(\mathrm{H}_{2} \mathrm{O} / \mathrm{ethanol}=\right.$ 1/1, $50.0 \mathrm{~mL}$ ) were added to a one neck round-bottom flask equipped with a condenser. The mixture was heated to $120{ }^{\circ} \mathrm{C}$ and left to stir at this temperature under reflux for three days. Samples were filtrated and refluxed in water and $1 \mathrm{M} \mathrm{HCl}$ for $2 \mathrm{hrs}$, respectively. The solid was collected by vacuum filtration, then washed with water and THF. The product was then subjected to Soxhlet extraction with THF as the solvent for one day to remove the trapped guest molecules. The solvent was then exchanged with anhydrous acetone and removed under vacuum at $80{ }^{\circ} \mathrm{C}$ giving JUC-505-COOH as a brown powder $(211.2 \mathrm{mg}, 95 \%)$. The degree of crystallinity was calculated from PXRD pattern by Jade as 90.3\%. Solid-state ${ }^{13} \mathrm{C}$ NMR (500 MHz) d: 163.2, 143.8, 137.8, 124.7, 108.6. IR (KBr): 3178, 3063, 2987, 2237, 1717, 1682, 1596, 1517, 1682, 1596, 1518, 1428, 1268,1190, 1021, 978, 921, $866 \mathrm{~cm}^{-1}$. Anal. Calcd: C, 64.18; H, 1.62. Found: C, 63.70; H, 1.59.

Synthesis of JUC-505-NH2. JUC-505 powder $(200.0 \mathrm{mg})$ and $\mathrm{LiAlH}_{4}(2.4 \mathrm{M}$ in THF, $30.0 \mathrm{~mL})$ were added to a one neck round-bottom flask equipped with a condenser. The mixture was heated to $90{ }^{\circ} \mathrm{C}$ and left to stir at this temperature under reflux for one day. After cooling down to room temperature, $1.0 \mathrm{~mL} 10 \% \mathrm{NaOH}$ was added dropwise to quench the reaction. $10.0 \mathrm{~mL} \mathrm{HCl}\left(\mathrm{HCl} / \mathrm{H}_{2} \mathrm{O}=2 / 1\right)$ was then added to the solution and stirred for $1 \mathrm{hr}$. The solid was collected by vacuum filtration, then washed with water. The residue powder was immersed in $20.0 \mathrm{~mL} 10 \% \mathrm{NaOH}$ to remove the extra acid and then exchanged with water until the solution became neutral. The solid was collected by vacuum filtration and washed with water and THF. The product was subjected to Soxhlet extraction with THF as the solvent for one day to remove the trapped guest molecules. The solvent was then exchanged with anhydrous acetone and removed under vacuum at $80{ }^{\circ} \mathrm{C}$ giving $\mathrm{JUC}-505-\mathrm{NH}_{2}$ as a brown powder 
(188.7 mg, 92\%). The degree of crystallinity was calculated from PXRD pattern by Jade as $88.2 \%$. Solid-state ${ }^{13} \mathrm{C}$ NMR (500 MHz) d: 145.5, 138.7, 125.0, 109.1, 25.0. IR (KBr): 3300, 3078, 2941, 2237 , 1634, 1587, 1515, 1264, 1186, 1144, 1022, 977, $867 \mathrm{~cm}^{-1}$. Anal. Calcd: C, 69.77; H, 3.51; N, 8.14. Found: C, 69.33; H, 3.38; N, 7.94.

Stability tests. The as-synthesized samples $(10.0 \mathrm{mg})$ were kept for 7 days in $20.0 \mathrm{~mL}$ of NMP, DMF, THF, DCM, EtOH, acetone, n-hexane, $m$-cresol, boiling water, $\mathrm{HCl}(12 \mathrm{M}), \mathrm{H}_{2} \mathrm{SO}_{4}(18 \mathrm{M}), \mathrm{HF}(40 \%)$, $\mathrm{NaOH}(14 \mathrm{M}), \mathrm{MeONa}(5 \mathrm{M}$ in $\mathrm{MeOH})$, chromic acid lotion (0.1 $\mathrm{M} \mathrm{K}_{2} \mathrm{Cr}_{2} \mathrm{O}_{7}$ in concentrate $\mathrm{H}_{2} \mathrm{SO}_{4}$ ) and $\mathrm{LiAlH}_{4}$ (2.4 M in THF). The samples were washed with $\mathrm{HCl}\left(\mathrm{HCl} / \mathrm{H}_{2} \mathrm{O}=2 / 1\right.$, for samples treated in $\mathrm{LiAlH}_{4}$ ), water (for samples treated in aqueous solutions), $\mathrm{MeOH}$ (for samples treated in $\mathrm{MeONa}$ ) and THF (for samples treated in organic solvents) respectively, followed by solvent exchanged by acetone and dried under vacuum at $85{ }^{\circ} \mathrm{C}$ for $12 \mathrm{hrs}$ and subjected to PXRD, IR and $\mathrm{N}_{2}$ adsorption analyses.

Sample activation. Before gas-/liquid-phase adsorption experiments, as-synthesized PAE-COFs (50.0 mg) were subjected to Soxhlet extraction with $\mathrm{H}_{2} \mathrm{O}$ and acetone as the solvents for one day to exchange the trapped guest molecules. Subsequently, it was collected by filtration and activated by drying under vacuum at $100{ }^{\circ} \mathrm{C}$ for $24 \mathrm{hrs}$.

Antibiotic uptake measurement. At room temperature, activated PAE-COFs (10.0 mg) was transferred to aqueous solutions $(20.0 \mathrm{~mL})$ containing given concentrations of TC, OTC or CTC (200.0 $\mathrm{mg} / \mathrm{L}$ ) at each $\mathrm{pH}$ value between 1 to 13 . After 3 days of soaking (for equilibrium adsorption), the solutions were filtrated and diluted to suitable concentration (among the linearity range of standard curves), and UV-Vis spectrophotometry of the solutions was performed to characterize the adsorption performances of PAE-COFs under specific conditions (360 nm for TC; $268 \mathrm{~nm}$ for OTC; $267 \mathrm{~nm}$ for CTC). The adsorbed amount Qe for antibiotics was calculated by using the mass balance Equation: Qe $=\left(\mathrm{C}_{0}-\mathrm{Ce}\right) \mathrm{V} / \mathrm{M}$, where $\mathrm{C}_{0}$ and $\mathrm{Ce}$ are the initial and equilibrium concentrations of solutions of antibiotics [mg L $\left.{ }^{-1}\right], \mathrm{V}$ is the volume of solution [L], and $\mathrm{M}$ the mass of adsorbent $[\mathrm{g}]$.

Characterization. ${ }^{1} \mathrm{H}$ NMR spectra were recorded on an AV400 NMR spectrometer. ${ }^{13} \mathrm{C}$ CP/MAS NMR spectra were recorded on an AVIII $500 \mathrm{MHz}$ solid-state NMR spectrometer. The FTIR spectra (KBr) were obtained using a SHIMADZU IRAffinity-1 Fourier transform infrared spectrophotometer. A SHIMADZU UV-2450 spectrophotometer was used for all absorbance measurements. TGA was 
carried out under nitrogen on a SHIMADZU DTG-60 thermal analyzer at a heating rate of $10{ }^{\circ} \mathrm{C} \mathrm{min}{ }^{-1}$ to $900{ }^{\circ} \mathrm{C}$ with $\mathrm{N}_{2}$ flow rate of $30 \mathrm{~mL} \mathrm{~min}{ }^{-1}$. Element analysis was carried out on a Germany Elementar large sample volume element analyzer, vario MACRO cube CHNS. PXRD data were collected on a PANalytical B.V. Empyrean powder diffractometer using a $\mathrm{Cu} \mathrm{K} \alpha$ source $(\lambda=1.5418 \AA$ ) over the range of $2 \theta=2.0-40.0^{\circ}$ with a step size of $0.02^{\circ}$ and $2 \mathrm{~s}$ per step. The sorption isotherm for $\mathrm{N}_{2}, \mathrm{CH}_{4}$ and $\mathrm{CO}_{2}$ was measured by using a Quantachrome Autosorb-IQ analyzer with ultra-high-purity gas (99.999\% purity). To estimate pore size distributions for PAE-COFs, nonlocal density functional theory (NLDFT) was applied to analyze the $\mathrm{N}_{2}$ isotherm on the basis of the model of $\mathrm{N}_{2} @ 77 \mathrm{~K}$ on carbon with slit pores and the method of non-negative regularization. The SEM images were obtained on JEOL JSM6700 scanning electron microscope. The TEM images and EDS spectra were obtained on JEM-2100 transmission electron microscopy. The gas-separation property was tested by breakthrough experiments using a $\mathrm{CO}_{2} / \mathrm{CH}_{4} / \mathrm{He}$ or $\mathrm{CO}_{2} / \mathrm{N}_{2} / \mathrm{He}(25: 25: 50 \mathrm{v} / \mathrm{v} / \mathrm{v})$ gas mixture at a flow rate of $2.0 \mathrm{~mL}$ $\min ^{-1}$ under room temperature. The relative amounts of the gases passing through the column were monitored on a Thermo Star gas analysis system detecting ion peaks at m/z+ $44\left(\mathrm{CO}_{2}\right), 16\left(\mathrm{CH}_{4}\right), 28$ $\left(\mathrm{N}_{2}\right), 4(\mathrm{He})$.

Data availability. The authors declare that the data supporting the findings of this study are available within the Article and its Supplementary Information files, or from the corresponding author on reasonable request.

\section{References}

(1) Côté, A. P. et al. Porous, crystalline, covalent organic frameworks. Science 310, 1166-1170 (2005).

(2) Colson, J. W. \& Dichtel, W. R. Rationally synthesized two-dimensional polymers. Nat. Chem. 5, 453-465 (2013).

(3) Huang, N., Wang, P. \& Jiang, D. L. Covalent organic frameworks: a materials platform for structural and functional designs. Nat. Rev. Mater. 1, 1-19 (2016).

(4) Diercks, C. S. \& Yaghi, O. M. The atom, the molecule, and the covalent organic framework. Science 355, 923-930 (2017).

(5) Ding, S. Y. \& Wang, W. Covalent organic frameworks (COFs): from design to applications. Chem. Soc. Rev. 42, 548-568 (2013). 
(6) Jin, Y. H., Hu, Y. M. \& Zhang, W. Tessellated multiporous two-dimensional covalent organic frameworks. Nat. Rev. Chem. 1, 0056 (2017).

(7) Kuhn, P., Antonietti, M. \& Thomas, A. Porous, covalent triazine-based frameworks prepared by ionothermal synthesis. Angew. Chem. Int. Ed. 47, 3450-3453 (2008).

(8) Furukawa, H. \& Yaghi, O. M. Storage of hydrogen, methane, and carbon dioxide in highly porous covalent organic frameworks for clean energy applications. J. Am. Chem. Soc. 131, 8875-8883 (2009).

(9) Guan, X. Y. et al. Fast, ambient temperature and pressure ionothermal synthesis of three-dimensional covalent organic frameworks. J. Am. Chem. Soc. 140, 4494-4498 (2018).

(10) Ding, S. Y. et al. Construction of covalent organic framework for catalysis: Pd/COF-LZU1 in suzuki miyaura coupling reaction. J. Am. Chem. Soc. 133, 19816-19922 (2011).

(11) Fang, Q. R. et al. 3D microporous base-functionalized covalent organic frameworks for size-selective catalysis. Angew. Chem., Int. Ed. 53, 2878-2882 (2014).

(12) Li, H. et al. 3D covalent organic frameworks with dual linkages for bifunctional cascade catalysis. J. Am. Soc. Chem. 138, 14783-14788 (2016).

(13) Han, X. et al. Chiral covalent organic frameworks with high chemical stability for heterogeneous asymmetric catalysis. J. Am. Chem. Soc. 139, 8693-8697 (2017).

(14) Wan, S., Guo, J., Kim, J., Ihee, H. \& Jiang, D. L. A belt-shaped, blue luminescent, and semiconducting covalent organic framework. Angew. Chem. Int. Ed. 47, 8826-8830 (2008).

(15) Bertrand, G. H. V., Michaelis, V. K., Ong, T. C., Griffin, R. G. \& Dincă, M. Thiophene-based covalent organic frameworks. Proc. Natl. Acad. Sci. USA 110, 4923-4928 (2013).

(16) Calik, M. et al. Extraction of photogenerated electrons and holes from a covalent organic framework integrated heterojunction. J. Am. Chem. Soc. 136, 17802-17807 (2014).

(17) Fang, Q. R. et al. 3D porous crystalline polyimide covalent organic frameworks for drug delivery. J. Am. Chem. Soc. 137, 8352-8355 (2015).

(18) Du, Y. et al. Ionic covalent organic frameworks with spiroborate linkage. Angew. Chem. Int. Ed. 55, 1737-1741 (2016). 
(19) Wang, S. et al. Exfoliation of covalent organic frameworks into few-layer redox-active nanosheets as cathode materials for lithium-ion batteries. J. Am. Chem. Soc. 139, 4258-4261 (2017).

(20) Sun, Q. et al. Postsynthetically modified covalent organic frameworks for efficient and effective mercury removal. J. Am. Chem. Soc. 139, 2786-2793 (2017).

(21) Li, Z. L. et al. Three-dimensional ionic covalent organic frameworks for rapid, reversible and selective ion exchange. J. Am. Chem. Soc. 139, 17771-17774 (2017).

(22) Lu, Q. Y. et al. Postsynthetic functionalization of three-dimensional covalent organic framework for selective extraction of lanthanide ions. Angew. Chem. Int. Ed. 57, 6042-6048 (2018).

(23) Kandambeth, S. et al. Self-templated chemically stable hollow spherical covalent organic framework. Nat. Common. 6, 6786 (2015).

(24) Mallick, A., Lukose, B., Mane, M. V., Heine, T. \& Banerjee, R. Construction of crystalline 2D covalent organic frameworks with remarkable chemical (acid/base) stability via a combined reversible and irreversible route. J. Am. Chem. Soc. 134, 19524-19527 (2012).

(25) Xu, H., Gao, J. \& Jiang, D. L. Stable, crystalline, porous, covalent organic frameworks as a platform for chiral organocatalysts. Nat. Chem. 7, 905-912 (2015).

(26) Wei, P. F. et al. Benzoxazole-linked ultrastable covalent organic frameworks for photocatalysis. $J$. Am. Chem. Soc. 140, 4623-4631 (2018).

(27) Hergenrother, P. M. The use, design, synthesis, and properties of high performance/high temperature polymers: an overview. High Performance Polymers 15, 3-45 (2003).

(28) Gao, Y. et al. Comparison of PEM properties of copoly(aryl ether ether nitrile)s containing sulfonic acid bonded to naphthalene in structurally different ways. Macromolecules 40, 1512-1520 (2007).

(29) Gotham, K. \& Turner, S. Poly(ether sulphone) as an engineering material. Polymer 15, 665-670 (1974)

(30) McKeown, N. B. \& Budd, P. M. Polymers of intrinsic microporosity (PIMs): organic materials for membrane separations, heterogeneous catalysis and hydrogen storage. Chem. Soc. Rev. 35, 675-683 (2006). 
(31) Materials Studio ver. 7.0, Accelrys Inc., San Diego, CA.

(32) Huang, N., Wang, P., Addicoat, M. A., Heine, T. \& Jiang, D. L. Ionic covalent organic frameworks: design of a charged interface aligned on 1D channel walls and its unusual electrostatic functions. Angew. Chem. Int. Ed. 56, 4982-4986 (2017).

(33) Du, N. et al. Polymer nanosieve membranes for $\mathrm{CO}_{2}$-capture applications. Nat. Mat. 10, 372-375 (2011).

(34) Henry, W. Experiments on the quantity of gases absorbed by water, at different temperatures, and under different pressures. Philos. Trans. R. Soc. Lond. 93, 29-42 (1803).

(35) Fang, Q. R. et al. Designed synthesis of large-pore crystalline polyimide covalent organic frameworks. Nat. Commun. 5, 4503 (2014).

(36) Guo J. et al. Conjugated organic framework with threedimensionally ordered stable structure and delocalized p clouds. Nat. Commun. 4, 2736 (2013).

(37) Halder A. et al. Ultrastable Imine-based Covalent Organic Frameworks for Sulfuric Acid Recovery: An Effect of Interlayer Hydrogen Bonding. Angew. Chem. Int. Ed. 57, 5797-5802 (2018).

(38) Katz, M. J. et al. A facile synthesis of UiO-66, UiO-67 and their derivatives. Chem. Commun. 49, 9449-9451 (2013).

(39) Pan, Y. C., Liu, Y. Y., Zeng, G. F., Zhao, L. \& Lai, Z. P. Rapid synthesis of zeolitic imidazolate framework-8 (ZIF-8) nanocrystalsin an aqueous system. Chem. Commun. 47, 2071-2073 (2011).

(40) Stephen, S. Y., Samuel, M. F., Jonathan, P. H., Charmant, A. \& Williams, I. D. A chemically functionalizable nanoporous material $\left[\mathrm{Cu}_{3}(\mathrm{TMA})_{2}\left(\mathrm{H}_{2} \mathrm{O}\right)_{3}\right]_{n}$. Science 283, 1148-1151 (1999).

(41) Eddaoudi, M. et al. Systematic design of pore size and functionality in isoreticular MOFs and their application in methane storage. Science 295, 469-472 (2002).

(42) Du, N., Robertson, G. P., Song, J., Pinnau, I. \& Guiver, M. D. High-performance carboxylated polymers of intrinsic microporosity (PIMs) with tunable gas transport properties. Macromolecules $\mathbf{4 2 ,}$ 6038-6043 (2009).

(43) Peng, C. et al. Diverse macroscopic helical motions of microribbons driven by electrons. Chem. Comm. 53, 2578-2581 (2017). 
(44) Sholl, D. S. \& Lively, R. P. Seven chemical separations to change the world. Nature 533, 316-322 (2016).

(45) Ali, I. New generation adsorbents for water treatment. Chem. Rev. 112, 5073-5091 (2012).

(46) Wang, T. et al. Adsorptive removal of antibiotics from water using magnetic ion exchange resin. $J$. Environ. Sci. 52, 111-117 (2017).

(47) Wang, Y., Pan, X., Wang, J., Hou, P. \& Qiang, Z. J. Adsorption behavior and mechanisms of norfloxacin onto porous resins and carbon nanotube. Chem. Eng. J. 179, 112-118 (2012).

(48) Ali, M. M. \& Ahmed, M. J. Adsorption behavior of doxycycline antibiotic on NaY zeolite from wheat (Triticum aestivum) straws ash. J. Institute Chem. Eng. 81, 218-224 (2017).

(49) Singh, S. et al. Nanocuboidal-shaped zirconium based metal organic framework for the enhanced adsorptive removal of nonsteroidal anti-inflammatory drug, ketorolac tromethamine, from aqueous phase. New J. Chem. 42, 1921-1930 (2018).

(50) Hayashi, H., Aratani, N. \& Yamada, H. Semiconducting self-assembled nanofibers prepared from photostable octafluorinated bisanthene derivatives. Chem. Eur. J. 23, 7000-7008 (2017).

(51) Mason, C. R. et al. Polymer of intrinsic microporosity incorporating thioamide functionality: preparation and gas transport properties. Macromolecules 44, 6471-6479 (2011).

(52) Jade version 5.0, Materials Data Inc., California.

\section{Acknowledgements}

Q.F., V.V., S.Q. and M.X. acknowledge the support of National Natural Science Foundation of China (21571079, 21621001, 21390394, 21571076 and 21571078), "111" project (B07016 and B17020), Guangdong and Zhuhai Science and Technology Department Project (2012D0501990028), and the program for JLU Science and Technology Innovative Research Team. Q.F and V.V. acknowledge the support from Thousand Talents program (China). V.V., Q.F., and S.Q. acknowledge the collaboration in the framework of China-French joint laboratory "Zeolites".

\section{Author contributions}

Q.F., V.V., Y.Y. and S.Q. were responsible for the overall design, direction and supervision of the project. X.G. performed the experimental work. H.L. and Y.M. took SEM images and helped with the 
TGA and PXRD tests. M.X. was in charge of other physical measurements. All authors discussed the results and contributed to the writing of the manuscript.

\section{Additional information}

Supplementary information is available in the online version of the paper. Reprints and permissions information is available online at www.nature.com/reprints. Correspondence and requests for materials should be addressed to Q.F., V.V., and Y.Y.

\section{Competing financial interests}

The authors declare no competing financial interests. 
a

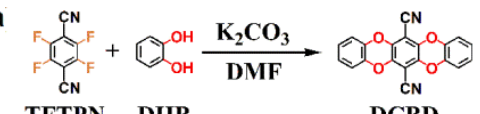

b

TFTPN DHB DCBD

TFTPN
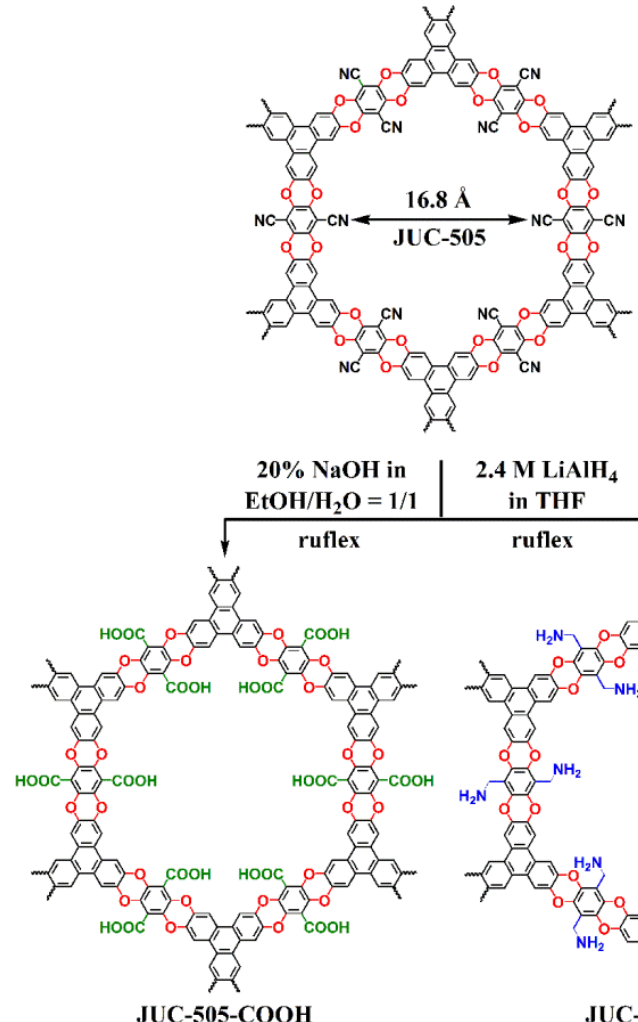

JUC-505-COOH
2.4 M LiAlH in THF

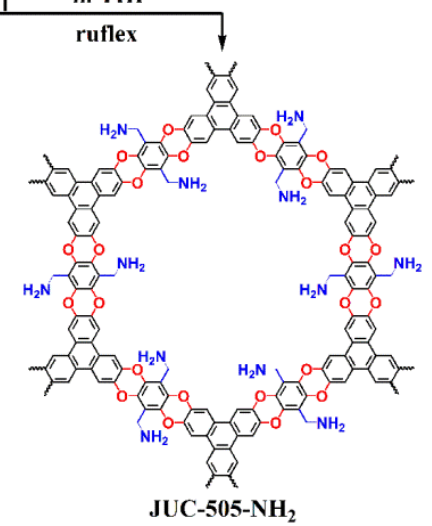

c

TFAQ

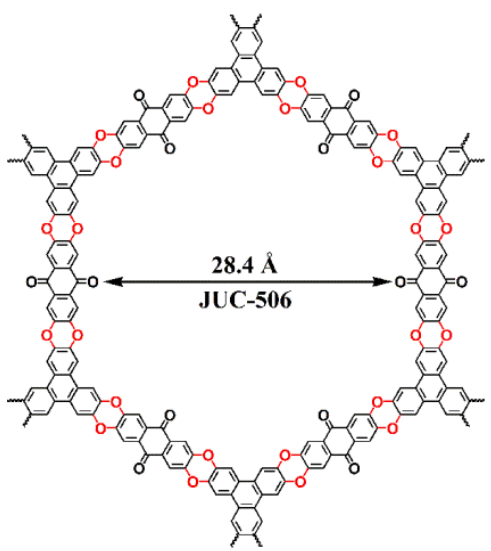

d

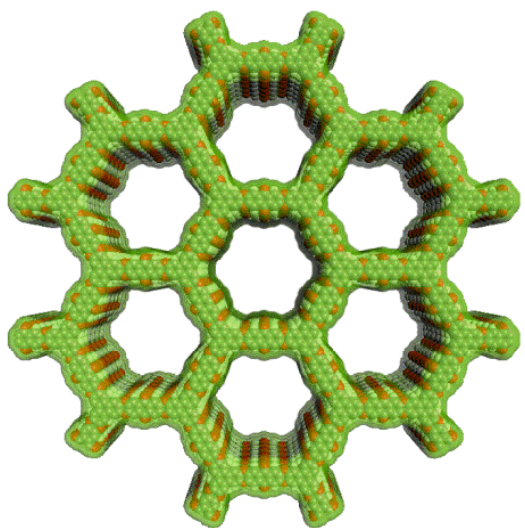

Figure 1 | Strategy for preparing stable porous crystalline PAE-COFs. a, The model reaction between TFTPN and DHB yields a dioxin product, DCBD. b, Condensation of TFTPN and HHTP gives a 2D microporous crystalline PAE-COF with pore size of $16.8 \AA$, denoted JUC-505. The functionalized PAE-COFs, JUC-505-COOH and JUC-505- $\mathrm{NH}_{2}$, can be obtained after the post-modification of JUC-505. c, TFAQ and HHTP forms a 2D mesoporous crystalline PAE-COF with pore size of $28.4 \AA$, denoted JUC-506. d, Condensation of linear and triangular building units constructs a 2D porous structure based on the boron nitride net (bnn). 
a
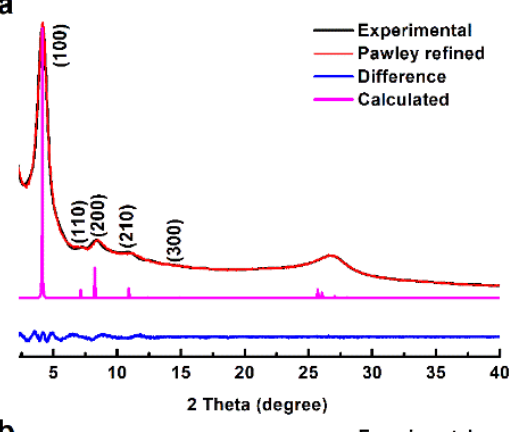

b

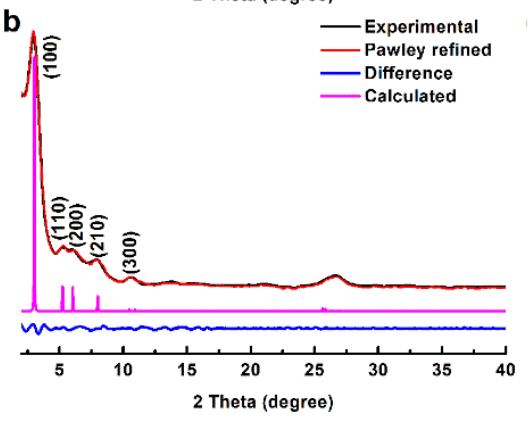

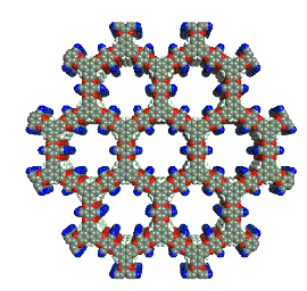

d

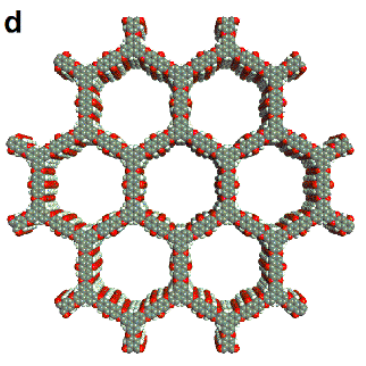

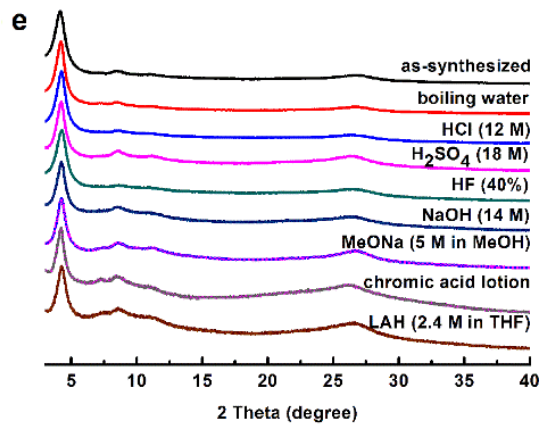

$f$ as-synthesized

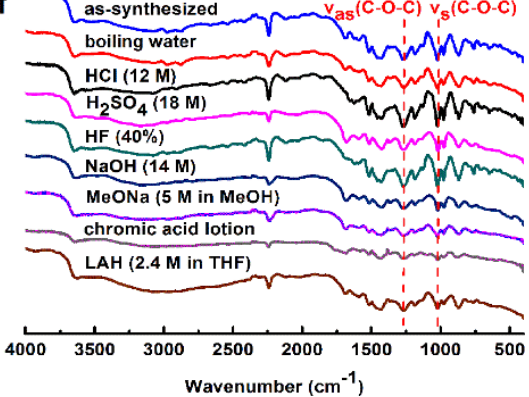

Figure 2 | Crystallinity and stability. a and b, PXRD profiles of JUC-505 and JUC-506, respectively.

Experimentally observed (black), Pawley refined (red), their difference (blue) and calculated using the AA stacking mode (magenta). c and d, Structure representation of the AA stacking mode of JUC-505 and JUC-506, respectively ( $\mathrm{O}$, red; $\mathrm{N}$, blue; $\mathrm{C}$, grey; $\mathrm{H}$, white). e and f, PXRD patterns and IR spectra of JUC-505 after treatments under different chemical environments for one week. 

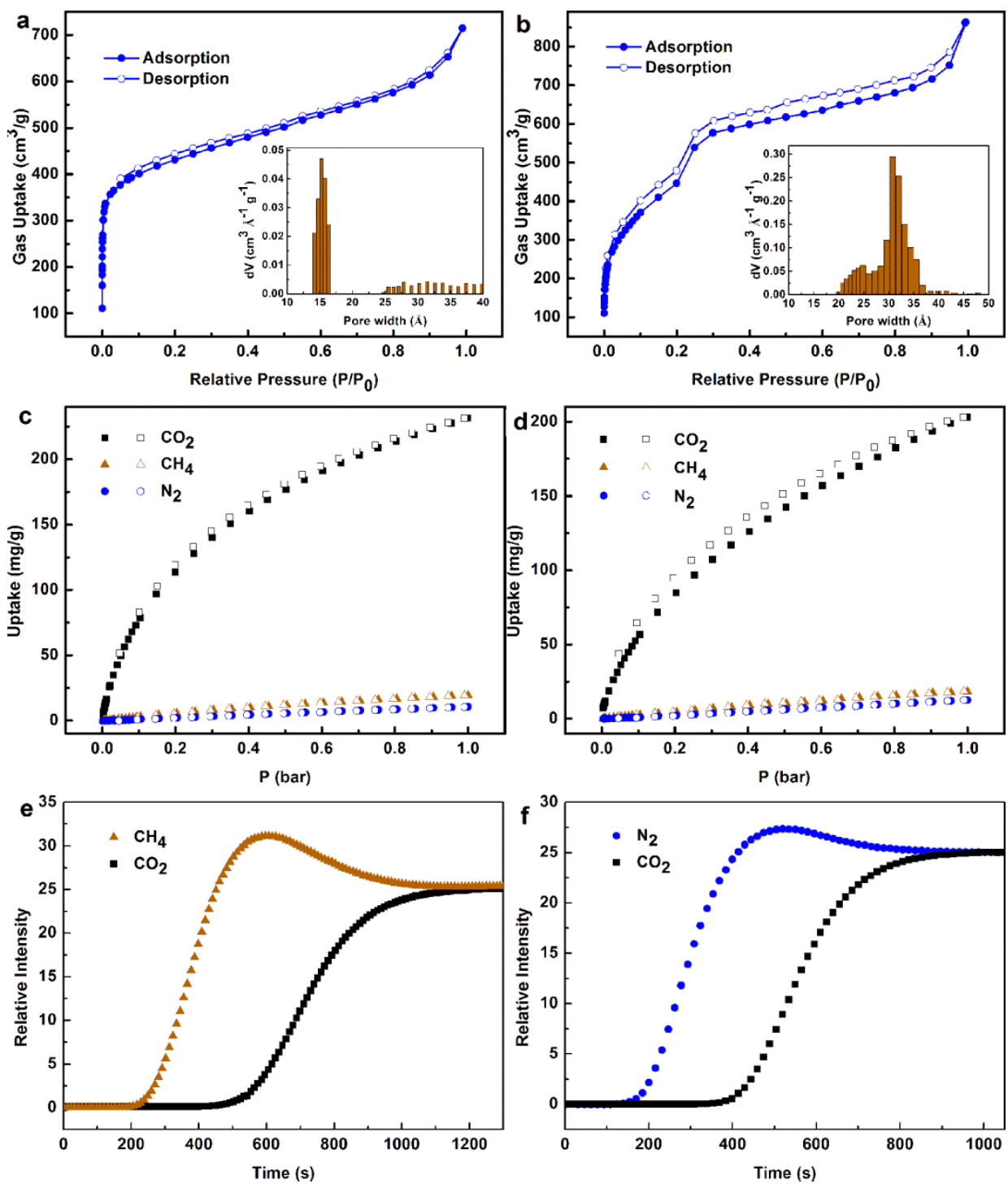

Figure 3 | Gas adsorption and separation. a and $\mathbf{b}, \mathrm{N}_{2}$ adsorption-desorption isotherms at $77 \mathrm{~K}$ for JUC-505 and JUC-506, respectively. Inset: pore size distributions from fitting the NLDFT model to the adsorption data. $\mathbf{c}$ and d, $\mathrm{CO}_{2}$ separation properties over $\mathrm{CH}_{4}$ and $\mathrm{N}_{2}$ at $273 \mathrm{~K}$ for JUC-505 and JUC-506, respectively. e and f, Breakthrough curves for JUC-505 using the $\mathrm{CO}_{2} / \mathrm{CH}_{4}$ and $\mathrm{CO}_{2} / \mathrm{N}_{2}$ gas mixture. 

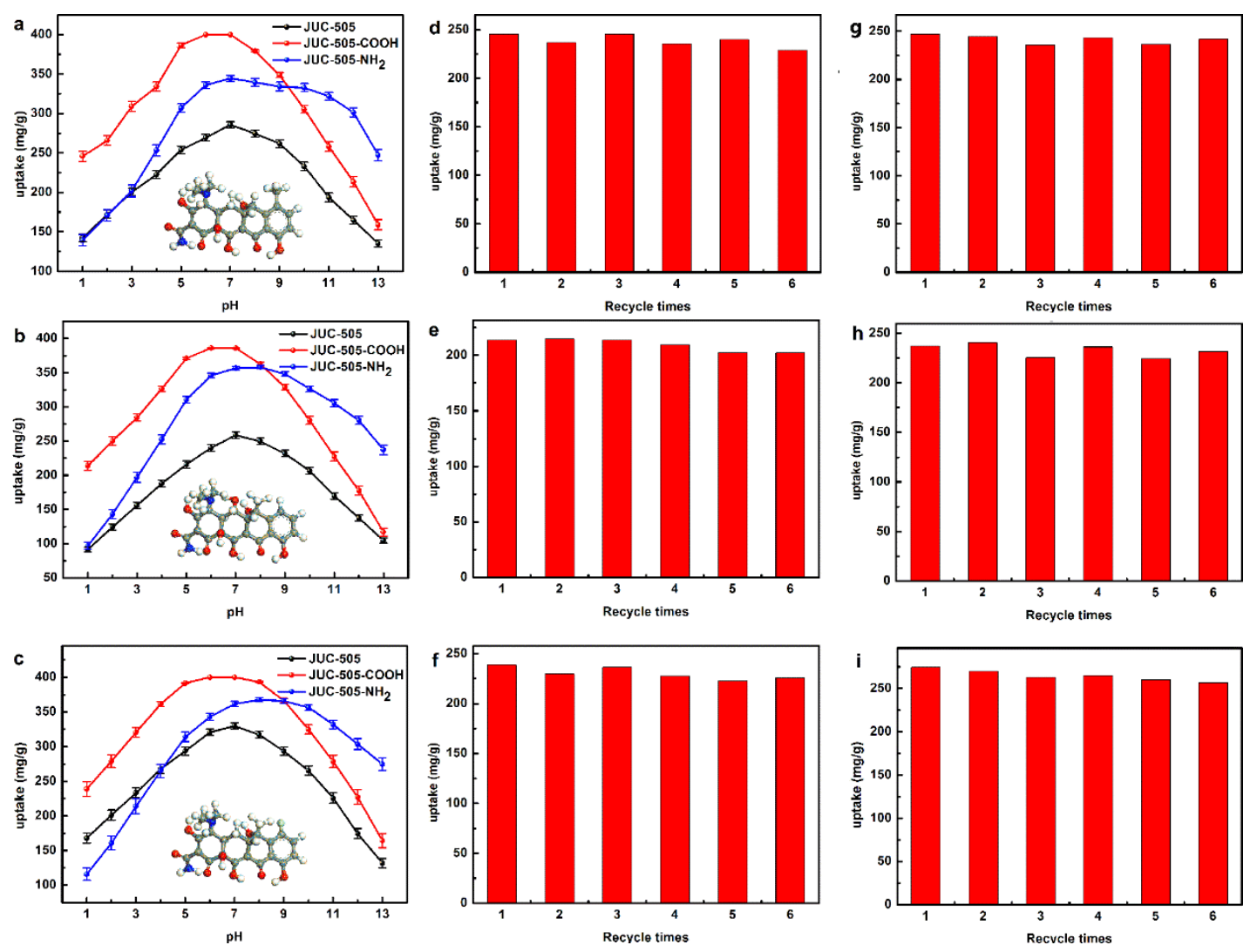

Figure 4 | Study of antibiotic uptakes. a-c, TCN, OTC and CTC uptakes at different $\mathrm{pH}$ (initial concentration $=200 \mathrm{mg} / \mathrm{L}$, contact time $=72 \mathrm{~h}$, sorbent dosage $=0.5 \mathrm{~g} / \mathrm{L}$, temperature $=298 \mathrm{~K}$ ). Inset: molecular structure of TCN, OTC and CTC. O, red; N, blue; C, grey; $\mathrm{H}$, white; $\mathrm{Cl}$, cyan. d-f, Recycling test of TCN, OTC and CTC uptakes of JUC-505-COOH at $\mathrm{pH}=1$. g-i, Recycling test of TCN, OTC and CTC uptakes of JUC-505- $\mathrm{NH}_{2}$ at $\mathrm{pH}=13$. 
Table 1 | Experimental and modelling results of gas adsorption on PAE-COFs.

\begin{tabular}{cccccccccc}
\hline $\begin{array}{c}\text { PAE } \\
\text {-COFs }\end{array}$ & BET & $\begin{array}{c}\text { Pore } \\
\text { volume }\end{array}$ & $\mathrm{LPD}^{[\mathrm{a}]}$ & Temperature & $\begin{array}{c}\text { Uptake } \\
\mathrm{mg} \mathrm{g}^{-1}\end{array}$ & \multicolumn{2}{c}{$\begin{array}{c}\text { Ideal adsorption } \\
\text { selectivity }\end{array}$} \\
& $\mathrm{m}^{2} \mathrm{~g}^{-1}$ & $\mathrm{~cm}^{3} \mathrm{~g}^{-1}$ & $\AA$ & $\mathrm{K}$ & $\mathrm{CO}_{2}$ & $\mathrm{CH}_{4}$ & $\mathrm{~N}_{2}$ & $\mathrm{CO}_{2} / \mathrm{CH}_{4}$ & $\mathrm{CO}_{2} / \mathrm{N}_{2}$ \\
\hline \multirow{2}{*}{ JUC-505 } & \multirow{2}{*}{1584} & \multirow{2}{*}{0.51} & \multirow{2}{*}{16.8} & 273 & 231.3 & 19.2 & 10.4 & 48.9 & 97.2 \\
& & & & 298 & 189.0 & 15.2 & 8.8 & 33.8 & 65.6 \\
JUC-506 & \multirow{2}{*}{1655} & 0.71 & 28.4 & 273 & 203.0 & 18.3 & 12.5 & 33.5 & 69.0 \\
& & & & 298 & 159.2 & 13.1 & 8.9 & 24.2 & 44.1 \\
\hline
\end{tabular}

${ }^{[\mathrm{a}]}$ Largest pore diameter (LPD) obtained theoretically; ${ }^{[\mathrm{b}]}$ Calculated using the initial slope in the Henry region of isotherms at $273 \mathrm{~K}$ and $298 \mathrm{~K}$ based on Henry's law. 
Table 2 | Stability after the treatment under various chemical environments for one week. ${ }^{[a]}$

\begin{tabular}{|c|c|c|c|c|c|c|c|c|c|}
\hline \multicolumn{2}{|r|}{ CPMs } & 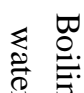 & $\Omega$ & J & $\underset{T}{T}$ & $\begin{array}{l}Z \\
0\end{array}$ & $\frac{3}{8}$ & 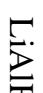 & 气 \\
\hline \multirow{9}{*}{ COFs } & JUC-505 & $\sqrt{ }$ & $\sqrt{ }$ & $\sqrt{ }$ & $\sqrt{ }$ & $\sqrt{ }$ & $\sqrt{ }$ & $\sqrt{ }$ & $\sqrt{ }$ \\
\hline & JUC-506 & $\sqrt{ }$ & $\sqrt{ }$ & $\sqrt{ }$ & $\sqrt{ }$ & $\sqrt{ }$ & $\sqrt{ }$ & $\sqrt{ }$ & $\sqrt{ }$ \\
\hline & DhaTab-COF $^{23}$ & $\sqrt{ }$ & $x$ & $\times$ & $x$ & $\times$ & $x$ & $\sqrt{ }$ & $\times$ \\
\hline & $\mathrm{TpPa}-1^{24}$ & $\sqrt{ }$ & $\sqrt{ }$ & $\times$ & $x$ & $\times$ & $x$ & $\sqrt{ }$ & $\times$ \\
\hline & TPB-DMTP-COF ${ }^{25}$ & $\sqrt{ }$ & $x$ & $x$ & $x$ & $\sqrt{ }$ & $\sqrt{ }$ & $x$ & $\times$ \\
\hline & LZU-190 26 & $\sqrt{ }$ & $x$ & $x$ & $\sqrt{ }$ & $\times$ & $x$ & $\sqrt{ }$ & $\times$ \\
\hline & PI-COF-2 ${ }^{35}$ & $\sqrt{ }$ & $x$ & $x$ & $x$ & $\times$ & $x$ & $\sqrt{ }$ & $\times$ \\
\hline & ${\mathrm{CS}-\mathrm{COF}^{36}}^{36}$ & $\sqrt{ }$ & $\sqrt{ }$ & $x$ & $x$ & $\times$ & $\times$ & $\sqrt{ }$ & $\times$ \\
\hline & $\mathrm{TpOMe} \mathrm{Pa} 1^{37}$ & $\sqrt{ }$ & $\sqrt{ }$ & $x$ & $\times$ & $\times$ & $x$ & $\sqrt{ }$ & $\times$ \\
\hline \multirow{4}{*}{ MOFs } & $\mathrm{UiO}-66^{38}$ & $\times$ & $\times$ & $x$ & $x$ & $x$ & $x$ & $x$ & $\times$ \\
\hline & ZIF- $8^{39}$ & $\times$ & $x$ & $\times$ & $x$ & $\times$ & $x$ & $x$ & $\times$ \\
\hline & HKUST- $1^{40}$ & $\times$ & $x$ & $x$ & $x$ & $\times$ & $x$ & $x$ & $\times$ \\
\hline & ${\mathrm{MOF}-5^{41}}^{4}$ & $\times$ & $x$ & $x$ & $\times$ & $\times$ & $x$ & $x$ & $\times$ \\
\hline \multirow{4}{*}{ Zeolites } & Silicalite- $1^{[\mathrm{b}]}$ & $x$ & $x$ & $x$ & $\times$ & $\times$ & $x$ & $x$ & $x$ \\
\hline & $\mathrm{X}^{[\mathrm{b}]}$ & $\times$ & $x$ & $x$ & $x$ & $x$ & $x$ & $x$ & $x$ \\
\hline & $\mathrm{Y}^{[\mathrm{b}]}$ & $\times$ & $x$ & $\times$ & $x$ & $x$ & $x$ & $x$ & $x$ \\
\hline & $4 \mathrm{~A}^{[\mathrm{b}]}$ & $x$ & $x$ & $x$ & $\times$ & $\times$ & $x$ & $x$ & $\times$ \\
\hline
\end{tabular}

${ }^{[a]}$ The stabilities of the samples were determined by PXRD patterns. Green with the tick represents stable, and red with the cross represents unstable.

${ }^{[b]}$ The chemicals were obtained from commercial sources. 